\title{
ENVIRONMENTAL DEVELOPMENT STRATEGY IN THE PLANNING REGIONS UNDER THE EFFECT OF CONTINUOUS OUTPUT OF THE SOLID WASTES
}

\author{
Suliman*, A. E. E. and Hegab**, K.K.
}

\begin{abstract}
The agricultural and municipal solid wastes are considered one of the main problems on the national, regional, and local level in Egypt. The main objective of this research is to construct environmental development strategic plan for the planning regions under continual generation of solid wastes. Data collection, manipulation, field study, and spatial analysis are carried out. Two sources of raw data were used for constructing the needed data base in this research. The first is the "Central Agency for Public Mobilization and Statistics" and the second is "Economic Affairs Sector in the Ministry of Agriculture and Land Reclamation" in Egypt. Field study for acquainting with the municipal solid wastes and its components in the local level in Egypt was carried through the summer season of 2010. Berk El Khyam village, Markaz Kerdasa, 6 Oct. Governorate was selected to be the core area of the field study. Ten points of planning principles and four planning alternatives were devised for environmental development strategy. The main recommendation is keeping in mind the ten principles and the four alternatives at preparation processes of the environmental development strategy for the regional planning.
\end{abstract}

\section{INTRODUCTION}

$\mathrm{M}$ unicipal solid waste (MSW) problems on the national, the regional, and the local levels; MSW management scenarios, efficiency, facilities; and MSW planning models, decision support systems were briefly summarized as follows:

Municipal solid waste management (including collection, treatment, and disposal) is considered a serious and visible environmental problem and public health risk.

*Prof. of Ag. Eng.

**Assist. Prof. of Ag. Eng. 
Of the 60 million tons of waste generation annually in Egypt municipal solid waste accounts for 15 million tons. The remaining include agricultural, construction and demolition wastes, industrial waste, water sludge, and waste from the clearing waterways. The quantity and composition of municipal solid waste varies from one to another. Average per capita waste generation is higher in urban areas (1.0 $\mathrm{kg} /$ person. day) than in rural areas $(0.3 \mathrm{~kg} /$ person. day $)$. It is worth noting that the volume of waste generated may be different from the volume of waste requiring final disposal. This is due to the fact that a portion of the waste generated is recovered through informal scavenging and recycling systems. Additionally, waste collection efficiency varies greatly from one area to another. In high income areas, collection efficiency can reach $60 \%$ in contrast to $10 \%$ collection efficiency in rural low income areas, CAPMS (2010).

Municipal solid waste components in Egypt are 50-60\% organic material, $10-25 \%$ paper, $3-12 \%$ plastic, $1-5 \%$ glass, $1.5-7 \%$ metals, $1.2-7 \%$ rags, and $11-30 \%$ others. The regional distribution of municipal solid waste in urban areas of Egypt are 52\% in Greater Cairo Region, 15\% Alexandria Region, 15.8\% Delta region, 6.8\% Canal Suez region, 3.9 North Upper Region, 2\% Assuit Region, and 4.4\% Southern Upper Egypt Region. Also, the regional distribution of municipal solid waste in rural areas of Egypt are 14\% in Greater Cairo Region, 10\% Alexandria Region, 33\% Delta region, 13\% Canal Suez region, 13\% North Upper Region, 5\% Assuit Region, and 12\% Southern Upper Egypt Region, CAPMS (2010).

Municipal solid waste management is a complex and multidisciplinary problem, involving a number of impact factors associated with various uncertainties, Zhang et al. (2010). Management of solid waste has received wide attention (economic, environmental and academic) because of the complex nature of these services. Technical and economic problems emerge in part because of rising demand due to income, population growth, arising level of urbanization, and a decline of suitable disposal sites, Noche (2010). 
Waste is a by-product of our daily activities, which poses a serious threat to societies all over the world. Three different municipal solid waste (MSW) management scenarios were developed and compared for the state of Kuwait. Scenario 1 represents the current MSW management status in Kuwait, involving collection, transport and land filling. Scenario 2 (direct incineration with energy recovery) incorporates a thermal treatment unit after the processing in a material recovery facility (MRF), while scenario 3 employs anaerobic digestion before land filling. The lowest contribution to the global warming category was calculated for the anaerobic digestion process (scenario 3), Al-Salem (2009). In Japan, the construction of new landfill facilities has become extremely difficult and the number of sites procured for landfill construction has decreased, Asakura, Matsuto, and Inoue (2010). Thorneloe et al. (2009) showed that the Municipal Solid Waste Decision Support Tool (MSWDST) can be used to quantify and evaluate the following impacts for each integrated solid waste management alternative: Energy consumption, Air emissions, Water pollutant discharges, Solid Waste disposal impacts. Recently, the MSW-DST was used by the U.S. EPA to identify solid waste management strategies that would help to meet the goal of the EPA's "Resource Conservation Challenge." In this effort, ten solid waste management strategies were evaluated for a hypothetical, medium-sized U.S. community. The U.S. Environmental Protection Agency launched the Resource Conservation Challenge in 2002 to help reduce waste and move towards more sustainable resource consumption.

In the regional plans, cooperation between prefectures and locate waste facilities to serve the entire region are needed. Therefore, a new multicriteria mixed-integer linear programming model to solve the locationallocation problem for municipal SWM at the regional level was used, Erkuta et al. (2008). Huang et al. (2002) mentioned that violation analysis is considered suitable approach for planning of regional solid waste management systems under uncertainty, based on an intervalparameter fuzzy integer programming (IPFIP) model. The comprehensive rational, incremental, adaptive, contingency, advocacy, 
and participatory models are considered six planning models as they relate to solid waste management, Hostovsky (2005).

Efficacy of waste recycling is one of the key determinants of environmental sustainability of a city. Like other pro-environmental activities, waste recycling cannot be successfully accomplished by just one or two people, but only by a concerted effort of the community, Yau (2010). The existing solid waste management approach in the city of Allahabad, India is highly unprofessional and lacking in scientific methodologies. There is neither proper collection nor proper treatment and disposal of waste. Most of the waste is dumped in low lying areas leading to pollution of land, air and water due to leach ate generation, Saxena et al. (2010). The existing solid waste management system in Kanpur city, India appears to be highly inefficient. Only primary and secondary collection, transportation and open dumping are practiced, that too in a non-technical manner, Zia and Devadas (2007). Saeed et al. (2009) mentioned that increased solid waste generation of Kuala Lumpur is alarming. For instance, the amount of daily residential SWG is found to be about $1.62 \mathrm{~kg} /$ capita; with the national average at $0.8-0.9 \mathrm{~kg} /$ capita and is expected to be increasing linearly, reaching to $2.23 \mathrm{~kg} / \mathrm{capita}$ by 2024. It is also found that, food (organic) waste is the major recyclable component followed by mix paper and mix plastics.

The location of multi-compartment sorted waste containers for recycling purposes in cities is an important problem in the context of urban waste management. The costs associated with those facilities and the impacts placed on populations are important concerns, Tralhão et al. (2010). MSW separation in five fractions: paper/cardboard, glass and lightweight packaging at drop-off points, organic waste and mixed waste in kerbside bins is considered the best collection system implemented in Spanish cities, Gallardo et al. (2010). Overall, 90\% of the households were not provided with the Nairobi City Council NCC waste storage bins nor was the waste collected regularly from the point of generation, Mutuku et al. (1997). MSW recycling can be promoted by encouraging separation at the source. Separation at the source can be achieved through financial 
incentives stimulation, legislation and raising of environmental awareness, Jasem (2005).

The total numbers of the agricultural and the municipal solid waste plants in Egypt is 69 with a capacity of 15 ton per hour, CAPMS (2008). Technically, the plant capacity ranges from 2 to 30 tons per hour, and from 10 to 600 tons per day.. Also, the maximum number operating hour is 20 hours per day with three shifts.

Planning and urban development in Egypt are accomplished through the concept of sustainable urban development that meets the need of the present and maintains the rights of the future generations. This development is executed from the preparation of strategic plans on the national, regional, governorate, city, and village levels. These plans determine the vision for executing the economic, social, urban, and environmental development, UCL \& ER (2008). Therefore, the main objective of this research is to construct planning principles, alternatives, and indicators of environmental development strategy plan for the planning regions under continual generation of the solid wastes.

\section{MATERIALS AND METHODS}

Collection and manipulation processes of raw data dealing with both agricultural and municipal solid wastes on the national, regional, and local levels in Egypt were carried out. Economic Affairs Sector (EAS) in the ministry of agriculture and land reclamation and Central Agency for Public Mobilization and Statistics (CAPMS) in Egypt are considered the main sources for getting the utilized raw data. Field study for acquainting the municipal solid wastes and its components in the local level in Egypt was carried out through the summer season of 2010. Berk El Khyam village, Markz Kirdasa, 6 Oct. Governorate was selected to be the core area of the field study. Two groups of the municipal solid waste samples were collected, transported, and separated into organic material, paper, plastic, glass, rag, metals, and other materials. The samples of the first group were directly collected from the residents. The samples of the second group were brought from the garbage lots in the village. General 
diagram of the utilized approach for getting rid of the agricultural and municipal solid wastes on the national, regional, and local levels in Egypt was designed. The literature review results, the manipulated data, and field study results were used for constructing eight principles, and four alternatives of the environmental development strategic plan for getting rid of both the agricultural and municipal solid wastes on the regional levels in Egypt.

Planning indicator design: Briefly, collection, transfer, treatment, and final disposal are considered the main steps in management processes of the agricultural and municipal solid wastes in the region. Numerically, the cost of each process could be changed due to the change of the local allocation of the solid waste recycling unit within the region. Since, the economic, the social, the physical, and the environmental conditions within the planning region are approximately homogenous. Therefore, the costs of the collection, the treatment, and the final disposal of the agricultural and municipal solid wastes are approximately constant for the all alternatives. Also, since the transportation distance and the available traffic speed are highly sensitive to any the change of the local allocation of the solid waste recycling units within the region. So, the transfer costs are considered the main constraint to select the best alternative of the development planning strategy in the planning region. Mathematically, the daily costs of the solid waste transfer could be expressed as:

$$
D C S W T=D G S W * C T * T C T H
$$

Where: DCSWT is the daily costs of the solid waste transfer (LE), DGSW is daily generation of the solid wastes (ton), CT is consumed time per travel in average for the solid wastes transfer (hour), and TCTH transfer cost for each ton per hour (LE/ton.h).

$$
C T=T D / A T S
$$

Where : $T D$ is transportation distance among the solid waste generation sources and the waste recycling units $(\mathrm{km})$, and ATS is available traffic speed on the road network among the solid waste generation sources and locations of the waste recycling units within the region $(\mathrm{km} / \mathrm{h})$. 
With the replacement of the values of the consumed time in equation (1) by its values in the in equation (2) the values of the transportation costs will be:

$$
D C S W T=D G S W *(T D / A T S) * T C T H
$$

This formula is considered an important indicator for selecting the best alternative of the local allocation of the solid waste recycling unit within the planning region. Therefore, the environmental development strategy has to be constructed on minimization of quantity of solid waste generation (QSW), minimization of solid waste transportation distance (TD), increasing the traffic efficiency for maximizing the available traffic speed (ATS), and minimizing transfer cost for ton per hour. Technically, efficient extension programs has to be followed for minimizing the solid waste generation, efficient allocation of the solid waste recycling unit for minimizing the solid waste transportation distance, efficient planning and design of the road network, and efficient management of the traffic for maximizing the available terrific speed, and efficient design and manufacture of the transportation means within the region.

Simulation layout design: For getting the needed data dealing with the sum of transportation distances for the all trips among the solid waste generation sources and the recycling units within the planning region a simulation layout was designed. For the simplicity of the calculation process of the sum of transportation distances the layout was designed on a panel of square pixels of $3 \times 3 \mathrm{~km}$. This layout consist of four governorates each of them contains urban and rural areas which broken down into Qism, Markaz, and Local Units, as shown in Fig. (1).

\section{RESULTS AND DISCUSSIONS}

Data Collection and Manipulation Results: Table (1) shows that the expected daily generation of the municipal solid wastes (MSW) in the five governorates of the Greater Cairo Region (GCR) is 14.983 thousand ton. Mathematically, these amounts of the MSW at least need 55 plants with capacity of 15 ton per hour at three shifts (18 hour operating time). Also, this table shows both the minimum and maximum amounts of the daily organic material, paper, plastic, glass, textile, metal, and other 
materials which could be produced from separation process of the generated MSW in the GCR. Mathematically, these amounts of the produced recycled materials are at least capable to feed 55 recycling plants with the needed raw materials.

This table shows the expected daily generation of the municipal solid wastes (MSW) in the main administration units in 6 Oct. Governorate. The expected daily generation of the (MSW) from the all administration units in 6 Oct. Governorate is 1.296 thousand ton. Mathematically, these amounts of the MSW at least need 5 plants with capacity of 15 ton per hour at three shifts (18 hour operating time). Unfortunately, 6 Oct. Governorate does not have any MSW plants. Land filling and dumping in the western desert are considered the main approach for MWS disposal. Also, this table shows both the minimum and maximum amounts of the daily organic material, paper, plastic, glass, textile, metal, and other materials which could be produced from separation process of the generated MSW in the main administration units in 6 Oct. Governorate. Mathematically, these amounts of the produced recycled materials are at least capable to feed 5 recycling plants with the needed raw materials.

This table shows the expected daily generation of the municipal solid wastes (MSW) from all the local administration units in Markaz Kirdasa is 136.935 ton. Mathematically, these amounts of the MSW at least need 2 medium scale plants with capacity of 10 ton per hour at two shifts ( 7 hour operating time). Numerically, the minimum amounts of the organic material, paper, plastic, glass, textile, metal, and other materials are expected to be $67.602,14.628,4.057,1.363,1.632,2.029,14.3873$ ton respectively. The maximum amounts of the organic material, paper, plastic, glass, textile, metal, and other materials are expected to be $81.121,33.800,16.225,5.960,9.463,9.463,40.559$ ton respectively. Mathematically, these amounts of the produced recycled materials are at least capable to feed 5 small scale recycling plants with the needed raw materials. 


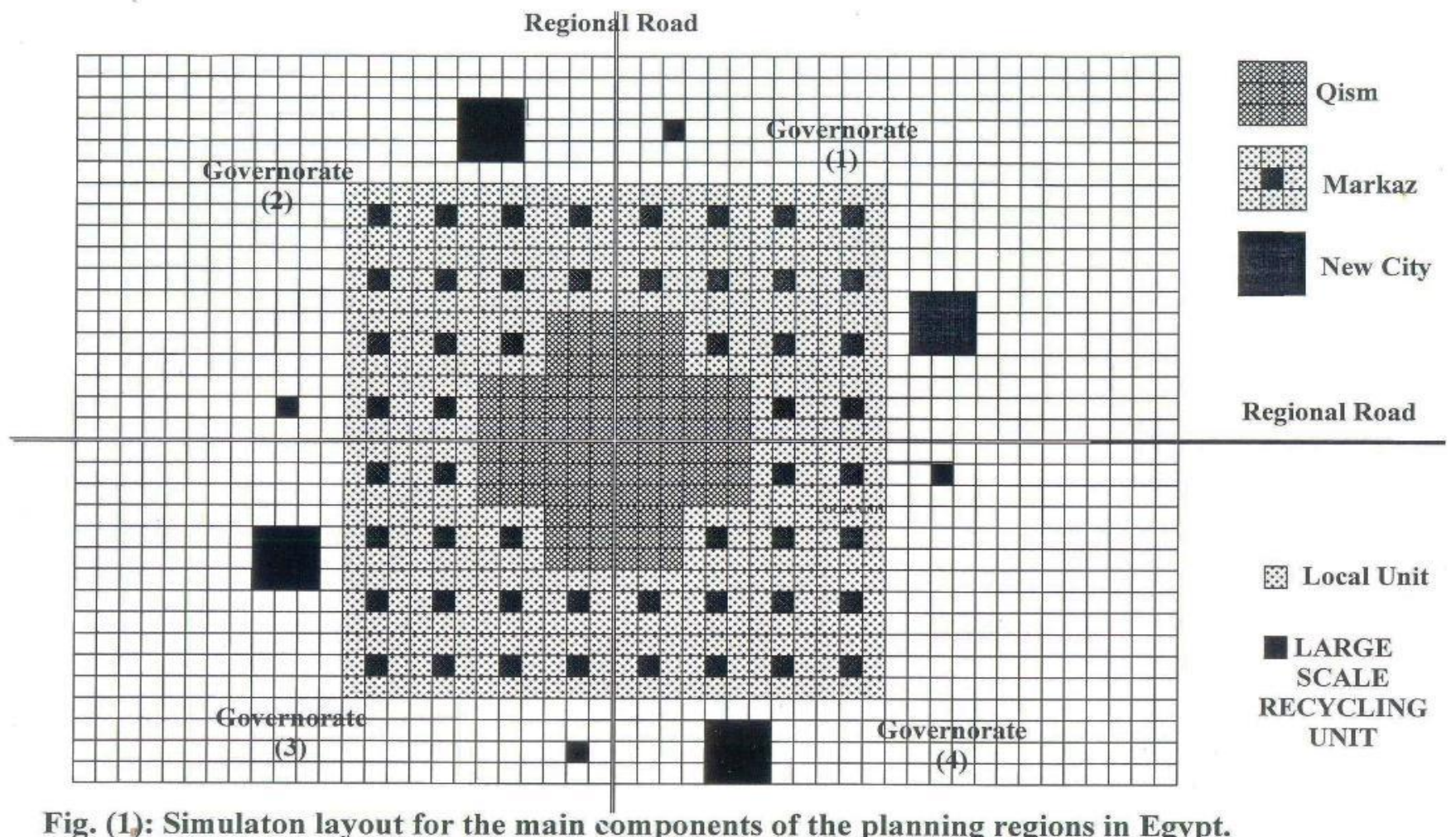


Table (1): Daily generation of the municipal solid waste on the national, regional, and governorate levels in Egypt.

\begin{tabular}{|c|c|c|c|c|c|c|c|c|c|c|c|c|}
\hline \multirow[t]{2}{*}{$\begin{array}{l}\text { G.C.R. } \\
\text { Govern. }\end{array}$} & \multicolumn{3}{|c|}{ Total population } & \multicolumn{5}{|c|}{$\begin{array}{l}\text { Municipals solid waste } \\
\qquad(\mathrm{kg} / \text { day })\end{array}$} & \multicolumn{2}{|c|}{$\begin{array}{l}\text { Organic material } \\
\qquad(\mathrm{kg} / \text { day })\end{array}$} & \multicolumn{2}{|c|}{$\begin{array}{c}\text { Paper } \\
\text { (kg/day) }\end{array}$} \\
\hline & \multicolumn{2}{|l|}{ Urban } & Rural & \multicolumn{2}{|c|}{ Urban } & \multicolumn{2}{|c|}{ Rural } & Total & $50 \%$ & $60 \%$ & $10 \%$ & $25 \%$ \\
\hline G.C.R. & \multicolumn{2}{|c|}{13497480} & 4950596 & \multicolumn{2}{|c|}{13497480} & \multicolumn{2}{|c|}{1485179} & 14982659 & 7491329 & 8989595 & 1498265 & 3745664 \\
\hline 6 Oct. & \multicolumn{2}{|l|}{745875} & 1835184 & \multicolumn{2}{|c|}{745875} & \multicolumn{2}{|c|}{550555} & 1296430 & 648215 & 777858 & 129643 & 324107 \\
\hline M. K. & \multicolumn{2}{|l|}{77121} & 196932 & \multicolumn{2}{|c|}{77121} & \multicolumn{2}{|c|}{59079} & 136200 & 68100 & 81720 & 13620 & 34050 \\
\hline \multirow[t]{2}{*}{$\begin{array}{l}\text { G.C.R. } \\
\text { Govern. }\end{array}$} & \multicolumn{3}{|c|}{$\begin{array}{c}\text { Plastic } \\
\text { (kg/day) }\end{array}$} & \multicolumn{2}{|c|}{$\begin{array}{c}\text { Glass } \\
\text { (kg/day) }\end{array}$} & & \multicolumn{2}{|c|}{$\begin{array}{c}\text { Rag } \\
\text { (kg/day) }\end{array}$} & \multicolumn{2}{|c|}{$\begin{array}{c}\text { Metals and Cans } \\
\text { (kg/day) }\end{array}$} & \multicolumn{2}{|c|}{$\begin{array}{c}\text { Other } \\
\text { (kg/day) }\end{array}$} \\
\hline & $3 \%$ & & $12 \%$ & $1 \%$ & $5 c$ & & $1.2 \%$ & $7 \%$ & $1.5 \%$ & $7 \%$ & $11 \%$ & $30 \%$ \\
\hline G.C.R. & 449479 & & 797919 & 149826 & 749 & & 179791 & 1048786 & 224739 & 1048786 & 1648092 & 4494797 \\
\hline 6 Oct. & 38892 & & 55571 & 12964 & 648 & & 15557 & 90750 & 19446 & 90750 & 142609 & 388929 \\
\hline M. K. & 4086 & & 16344 & 1362 & 68 & & 1634 & 9534 & 2043 & 9534 & 14982 & 40860 \\
\hline
\end{tabular}

Where: G.C.R. is Greater Cairo Region, 6 Oct. is 6 October governorate, and M.K. is Markas Kerdasa. 
Table (2) shows the expected daily generation of the municipal solid wastes (MSW) from all villages of markaz Kerdas are from 2.379 to 18.096 ton. Practically, small scale plants at least need 15 ton of the MSW per day. Therefore, one small scale plant is enough for 2-3 villages. The amounts of the produced recycled materials are at least capable to feed 2-3 small scale recycling plants with the needed raw materials.

The Agricultural Waste: Table (3) shows the amounts of the annual agricultural solid residues produced only from the field crops in Egypt. Unfortunately, publication of official data deals with the annual agricultural solid residues produced from both orchards and vegetables in Egypt is not found. However, the amount of the annual agricultural solid residues produced only from the field crops in Egypt is 29.337 million ton in average. Mathematically, these amounts of the agricultural wastes at least need 14 plants with capacity of 15 ton per hour at two shifts (12 hour operating time).

This table shows the amounts of the annual agricultural sold residues produced from the field crops only in the GCR is 0.867 million ton in average. Mathematically, these amounts of the agricultural wastes at least need 14 plants with capacity of 15 ton per hour at two shifts (12 hour operating time). Mathematically, these amounts of the produced recycled materials are at least capable to feed 15-50 different scale feeding industry plants with the needed raw materials. The amounts of the annual agricultural solid residues produced from the field crops only in Coiro, Giza, Helwan, Qalubia, and 6 Oct. City are 275, 8402, 470375, 70383, and 226714 ton respectively. Mathematically, these amounts of the produced recycled materials in 6 Oct, are at least capable to feed 5-10 small scale feeding industry plants with the needed raw materials.

Field Study Results: Table (4) shows the main components and masses in the fresh trash sample collected from the residents of Berk El Khyam village. Percentage of the organic material, paper, plastic, glass, textile, metal, and other materials are 48.67, 22.74, 9.68, 5.16, 3.85, 2.09, and $7.81 \%$ respectively. 
Table (2): Daily generation of the municipal solid waste in Markaz Kerdasa.

\begin{tabular}{|c|c|c|c|c|c|c|c|c|c|c|}
\hline \multirow[t]{2}{*}{$\begin{array}{c}\text { Local } \\
\text { Administration Units }\end{array}$} & \multirow{2}{*}{\multicolumn{2}{|c|}{$\begin{array}{c}\text { Total } \\
\text { population }\end{array}$}} & \multirow{2}{*}{\multicolumn{2}{|c|}{$\begin{array}{c}\text { Municipal } \\
\text { solid waste } \\
\text { (kg/day) }\end{array}$}} & \multicolumn{3}{|c|}{$\begin{array}{c}\text { Organic material } \\
(\mathrm{kg} / \text { day })\end{array}$} & \multicolumn{3}{|c|}{$\begin{array}{c}\text { Paper } \\
\text { (kg/day) }\end{array}$} \\
\hline & & & & & $50 \%$ & \multicolumn{2}{|l|}{$60 \%$} & $10 \%$ & \multicolumn{2}{|c|}{$25 \%$} \\
\hline Kerdasa City & \multicolumn{2}{|c|}{77121} & \multicolumn{2}{|c|}{77121} & 38561 & \multicolumn{2}{|c|}{46273} & 7712 & \multicolumn{2}{|c|}{19280} \\
\hline Nahya Village & \multicolumn{2}{|c|}{47533} & \multicolumn{2}{|c|}{14260} & 7130 & \multicolumn{2}{|c|}{8556} & 1426 & \multicolumn{2}{|r|}{3565} \\
\hline Berk El Khyam Village & \multicolumn{2}{|c|}{15320} & \multicolumn{2}{|c|}{4596} & 2298 & \multicolumn{2}{|c|}{2758} & 460 & \multicolumn{2}{|r|}{1149} \\
\hline El Moatamadya Village & \multicolumn{2}{|c|}{60875} & \multicolumn{2}{|c|}{18262} & 9131 & \multicolumn{2}{|c|}{10958} & 1826 & \multicolumn{2}{|r|}{4566} \\
\hline Abo Rawash Village & \multicolumn{2}{|c|}{18863} & \multicolumn{2}{|c|}{5659} & 2830 & \multicolumn{2}{|c|}{3395} & 566 & \multicolumn{2}{|r|}{1415} \\
\hline Bany Magdool Village & \multicolumn{2}{|c|}{22389} & \multicolumn{2}{|c|}{6717} & 3359 & \multicolumn{2}{|c|}{4030} & 1679 & \multicolumn{2}{|r|}{1679} \\
\hline Kombara Village & \multicolumn{2}{|c|}{7929} & \multicolumn{2}{|c|}{2379} & 1189 & 1427 & & 238 & & 595 \\
\hline Kafr Hakeem Village & \multicolumn{2}{|c|}{24023} & 720 & & 3603 & 4324 & & 721 & & 1801 \\
\hline & & & & & & & & & & her \\
\hline & $3 \%$ & $12 \%$ & $1 \%$ & $5 \%$ & $1.2 \%$ & $7 \%$ & $1.5 \%$ & $7 \%$ & $11 \%$ & $30 \%$ \\
\hline Kerdasa City & 2314 & 9255 & 771 & 3056 & 925 & 5398 & 1157 & 5398 & 8483 & 23136 \\
\hline Nahya Village & 428 & 1711 & 143 & 713 & 171 & 998 & 214 & 998 & 1569 & 4278 \\
\hline Perk El Khyam Village & 138 & 552 & 46 & 230 & 55 & 322 & 69 & 322 & 506 & 1379 \\
\hline El Moatamadya Village & 548 & 2192 & 183 & 913 & 219 & 1278 & 274 & 1278 & 2009 & 5477 \\
\hline Abo Rawash Village & 170 & 679 & 57 & 283 & 68 & 396 & 85 & 396 & 622 & 1698 \\
\hline Bany Magdool Village & 202 & 806 & 67 & 336 & 81 & 470 & 101 & 470 & 739 & 2015 \\
\hline Kombara Village & 71 & 285 & 24 & 119 & 29 & 166 & 36 & 166 & 262 & 714 \\
\hline Kafr Hakeem Village & 216 & 864 & 72 & 360 & 86 & 504 & 108 & 504 & 792 & 2162 \\
\hline
\end{tabular}


Table (3): Annual agricultural solid waste on the national, regional, and governorate levels in Egypt. (ton/year)

\begin{tabular}{|c|c|c|c|c|c|c|c|}
\hline Type of ag. waste & Egypt & G.CR. & Cairo & Giza & Kalubya & 6 Oct. & Helwan \\
\hline Wheat straw & 8921188 & 230968 & 203 & 1271 & 144675 & 73872 & 10947 \\
\hline Barly straw & 181829 & 1346 & 5 & ---- & ---- & 851 & 490 \\
\hline Chickpea straw & 9142 & $\begin{array}{ll}--- \\
--1\end{array}$ & $\begin{array}{ll}--- \\
\end{array}$ & $\begin{array}{l}--- \\
\end{array}$ & $\begin{array}{ll}--- \\
\end{array}$ & $\begin{array}{ll}--- \\
\end{array}$ & $\begin{array}{ll}--- \\
--1\end{array}$ \\
\hline Feba bean Straw & 354950 & 113 & ---- & ---- & 113 & ---- & ---- \\
\hline Ring straw & 11013 & ---- & ---- & $\begin{array}{ll}--- \\
--\end{array}$ & --- & $\begin{array}{ll}--- \\
--\end{array}$ & $\begin{array}{ll}--- \\
--\end{array}$ \\
\hline Clover straw & 135681 & 2171 & $\begin{array}{l}--- \\
--1\end{array}$ & 56 & 616 & 297 & 1202 \\
\hline Sugar beet residues & 1036835 & 3731 & ---- & 1865 & 68 & 822 & 976 \\
\hline Cotton stalk & 511032 & 2152 & ---- & ---- & 2152 & --- & --- \\
\hline Corn stover & 5242306 & 435375 & 53 & 4458 & 299825 & 97216 & 33823 \\
\hline Peanut straw & 862872 & 5638 & ---- & ---- & 622 & 4985 & 31 \\
\hline Sorghum stalk & 870624 & 3482 & ---- & ---- & ---- & 3482 & ---- \\
\hline Rice straw & 2909239 & 22371 & 15 & $\begin{array}{ll}--- \\
\end{array}$ & 22356 & $\begin{array}{c}--- \\
\end{array}$ & $\begin{array}{ll}--- \\
-1\end{array}$ \\
\hline Sesame stalk & 137627 & 3148 & ---- & ---- & 37 & 2611 & 500 \\
\hline Sun flower stalk & 52296 & 247 & ---- & ---- & 13 & 234 & ---- \\
\hline Soybean stalk & 80717 & 112 & ---- & ---- & 112 & ---- & ---- \\
\hline Sugar cane residues & 7476339 & 11241 & ---- & 159 & 11082 & ----- & ---- \\
\hline Total mass & 28793690 & 712095 & 276 & 7809 & 481671 & 184370 & 47969 \\
\hline
\end{tabular}


Fortunately, these ratios are located within the range of the MSW components mentioned in, CAPSS (2010). Also, Table (5) shows the main components and masses in stale MWS samples collected from garbage lots in Berk El Khyam village. Percentages of the organic material, paper, plastic, glass, textile, metal, and other materials are $44.89,18.75,7.73,5.52,1.80,2.73$, and $18.58 \%$ respectively. Due to the activity of the illegal scavengers, percentages of the organic material, paper, plastic, and metal in the fresh samples are greater than its values in the stale samples collected from the garbage lots, Fig. (2).

Spatial Analysis Results: Fig. (3) summarizes the present approaches for getting rid of both the agricultural and the municipal solid wastes in the planning regions in Egypt. On land combustion is considered the major approach for getting rid of the agricultural solid wastes (field residues) such as rice straw in Delta and sugar cane dry leaves in Upper Egypt Regions. Collection, transport, composting, and recycling are considered minor approaches for getting rid of the agricultural solid wastes (field residues) in the Egyptian Regions. Municipal solid waste accumulation on the vacant lands, the main roads, and the irrigation channels is considered one of the main aspects of the Egyptian villages. Collection, transport, composting, and recycling are considered minor approaches for getting rid of $60 \%$ of the MSW of the urban areas in the Egyptian Regions. Land filling and dumping are considered the major approach for getting rid of the collected MSW from the urban areas in the Egyptian Regions. Due to technical, economic, and social problems both the composting and the recycling approach for utilization of the collected part of the MSW as an economic resource is still limited in the Egyptian planning regions. Briefly, W11, W12, and W13 are assumed symbols expressing generation of both the agricultural and the municipal solid wastes from Local Unit, Rural Markaz, and urban area respectively. R21, R22, and R23 are assumed symbols expressing on the management results of the agricultural and the municipal solid wastes in Local Unit, Rural Markaz, and urban area respectively. 
Table (4): Components of the fresh municipal solid waste in Berk El Khyam village. (kg)

\begin{tabular}{|c|c|c|c|c|c|c|c|c|}
\hline \multicolumn{7}{|c|}{ Sample Specification } & \multicolumn{7}{|c|}{ Sample Specification } \\
\hline No. & Mass & Organic & Paper & Plastic & Glass & Metal & Rag & Other \\
\hline 1 & 120 & 67.2 & 26.4 & 6.00 & 4.8 & 3.6 & 6 & 6 \\
\hline 2 & 150 & 81.0 & 30.0 & 12.0 & 7.5 & - & 4.5 & 15 \\
\hline 3 & 110 & 57.2 & 25.3 & 9.90 & 3.3 & 5.5 & 4.4 & 4.4 \\
\hline 4 & 135 & 59.2 & 33.75 & 14.85 & 8.1 & 9.45 & - & 9.45 \\
\hline 5 & 128 & 67.84 & 29.44 & 12.8 & 10.24 & - & - & 7.68 \\
\hline 6 & 136 & 61.68 & 28.56 & 10.4 & 4.08 & 6.8 & 8.16 & 16.32 \\
\hline 7 & 113 & 57.63 & 22.6 & 15.82 & 9.04 & 7.91 & - & - \\
\hline 8 & 107 & 51.36 & 24.61 & 7.49 & 3.21 & - & 4.28 & 16.05 \\
\hline 9 & 124 & 60.76 & 22.32 & 12.4 & 6.2 & 11.16 & - & 11.16 \\
\hline 10 & 115 & 58.30 & 32.2 & 7.25 & - & 5.75 & - & 11.5 \\
\hline 11 & 97 & 37.83 & 24.25 & 10.67 & 7.76 & 6.79 & 1.94 & 7.76 \\
\hline 12 & 133 & 69.86 & 35.91 & 11.28 & 5.32 & 7.98 & - & 2.66 \\
\hline 13 & 105 & 40.33 & 25.07 & 16.35 & 10.9 & 5.45 & - & 10.9 \\
\hline 14 & 123 & 67.65 & 22.14 & 9.84 & 2.46 & - & 8.61 & 12.3 \\
\hline 15 & 104 & 43.68 & 26 & 10.4 & 10.4 & - & - & 13.52 \\
\hline 16 & 134 & 61.64 & 32.16 & 20.1 & 6.7 & 4.02 & 2.68 & 6.7 \\
\hline Mass & $\mathbf{1 9 3 8}$ & $\mathbf{9 4 3 . 3 2}$ & $\mathbf{4 4 0 . 7 1}$ & $\mathbf{1 8 7 . 5 5}$ & $\mathbf{1 0 0 . 0 1}$ & $\mathbf{7 4 . 4}$ & $\mathbf{4 0 . 5 7}$ & $\mathbf{1 5 1 . 4}$ \\
\hline \% & $\mathbf{1 0 0}$ & $\mathbf{4 8 . 6 7}$ & $\mathbf{2 2 . 7 4}$ & $\mathbf{9 . 6 8}$ & $\mathbf{5 . 1 6}$ & $\mathbf{3 . 8 5}$ & $\mathbf{2 . 0 9}$ & $\mathbf{7 . 8 1}$ \\
\hline
\end{tabular}


Table (5): Components of the stale municipal solid waste in Berk El Khyam village. (kg)

\begin{tabular}{|c|c|c|c|c|c|c|c|c|}
\hline \multicolumn{2}{|c|}{ Sample Specification } & \multicolumn{7}{|c|}{ Sample Components } \\
\hline No. & Mass & Organic & Paper & Plastic & Glass & Metal & Rag & Other \\
\hline 1 & 90.30 & 46.3 & 17.2 & 2.2 & 5.1 & 1.5 & 4.5 & 13.5 \\
\hline 2 & 106.7 & 53.5 & 15.2 & 7.7 & 6.5 & 2.3 & 3.6 & 17.9 \\
\hline 3 & 84 & 39.7 & 13.6 & 4.75 & 2.25 & 2.6 & 4.8 & 16.3 \\
\hline 4 & 96.94 & 41.2 & 20.65 & 8.13 & 5.2 & 4.16 & 3.5 & 14.1 \\
\hline 5 & 100.1 & 46.4 & 11.60 & 5.5 & 6.5 & 1.3 & 5.3 & 23.5 \\
\hline 6 & 88.1 & 33.50 & 19.30 & 6.6 & 13 & - & & 15.7 \\
\hline 7 & 87.93 & 25.7 & 17.5 & 9.5 & 11.1 & 3.3 & 1.7 & 19.13 \\
\hline 8 & 86.60 & 43.1 & 15.7 & 3.8 & 6.3 & - & 3.8 & 14.5 \\
\hline 9 & 81.16 & 33.16 & 18.5 & 8.5 & 3.7 & - & $=$ & 17.3 \\
\hline 10 & 86.22 & 38.1 & 23.75 & 5.12 & 1.5 & 3.6 & 1.5 & 12.75 \\
\hline 11 & 71.70 & 26.5 & 17.5 & 9.3 & - & - & 2.75 & 15.65 \\
\hline 12 & 87.40 & 41.35 & 17.8 & 5.5 & 3.4 & 2.5 & $=$ & 16.85 \\
\hline 13 & 81.45 & 32.17 & 15.13 & 8.75 & 2.9 & - & - & 22.5 \\
\hline 14 & 101.02 & 53.5 & 18.5 & 5.22 & - & 1.5 & 6 & 16.3 \\
\hline 15 & 75.08 & 32.13 & 11.35 & 7.5 & 1.5 & - & $=$ & 22.6 \\
\hline 16 & 115.61 & 51.3 & 13.11 & 12.25 & 9.5 & 2.7 & 1.3 & 25.40 \\
\hline Mass & 1420.31 & 637.61 & 266.28 & 109.72 & 78.45 & 25.51 & 38.75 & 263.98 \\
\hline$\%$ & 100 & 44.89 & 18.75 & 7.73 & 5.52 & 1.8 & 2.73 & 18.58 \\
\hline
\end{tabular}


Fig. (2): Components of the MWS in one of the rural villages in 6 Oct. Governorate.

(Berk El Khyam)

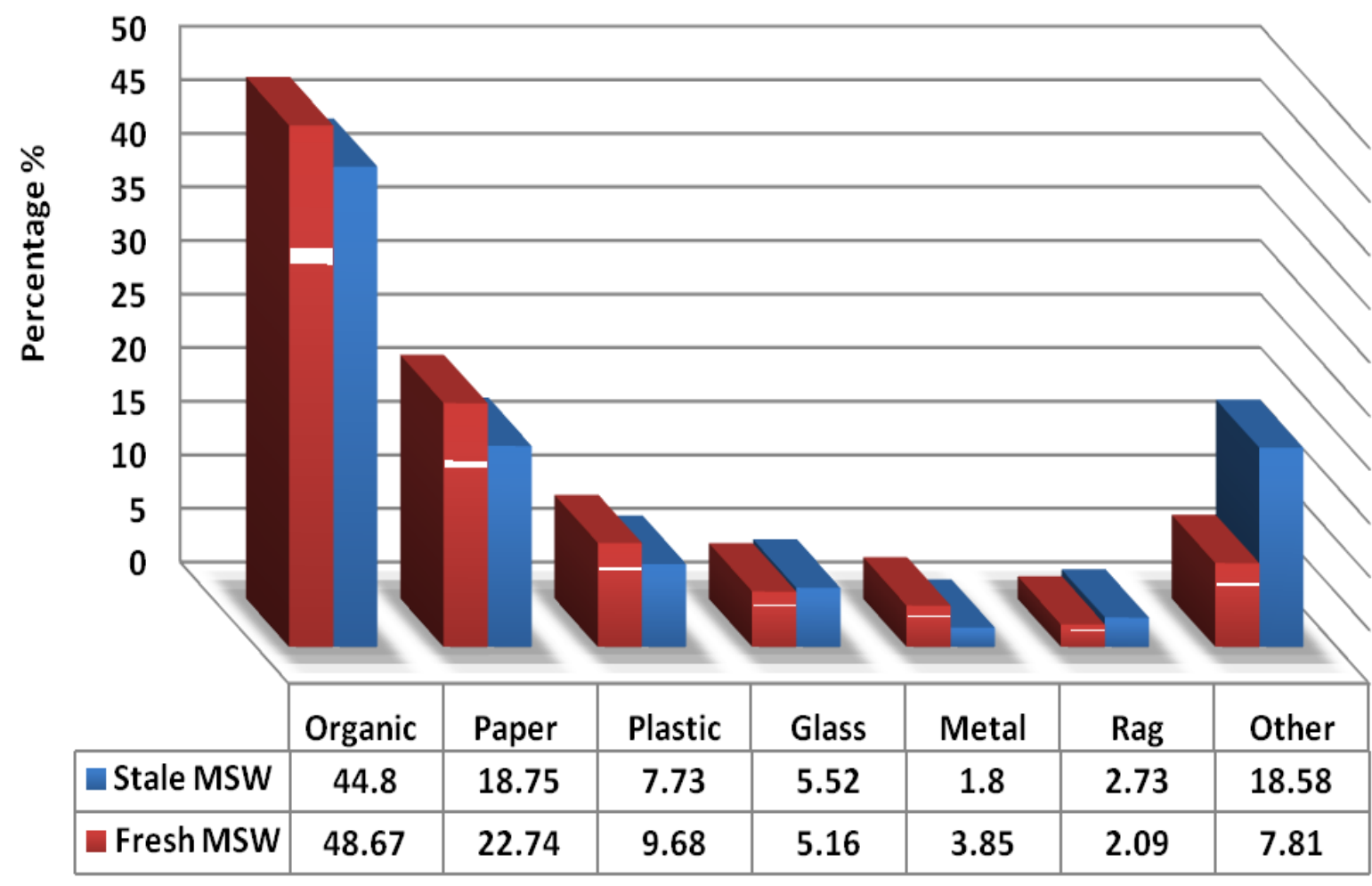




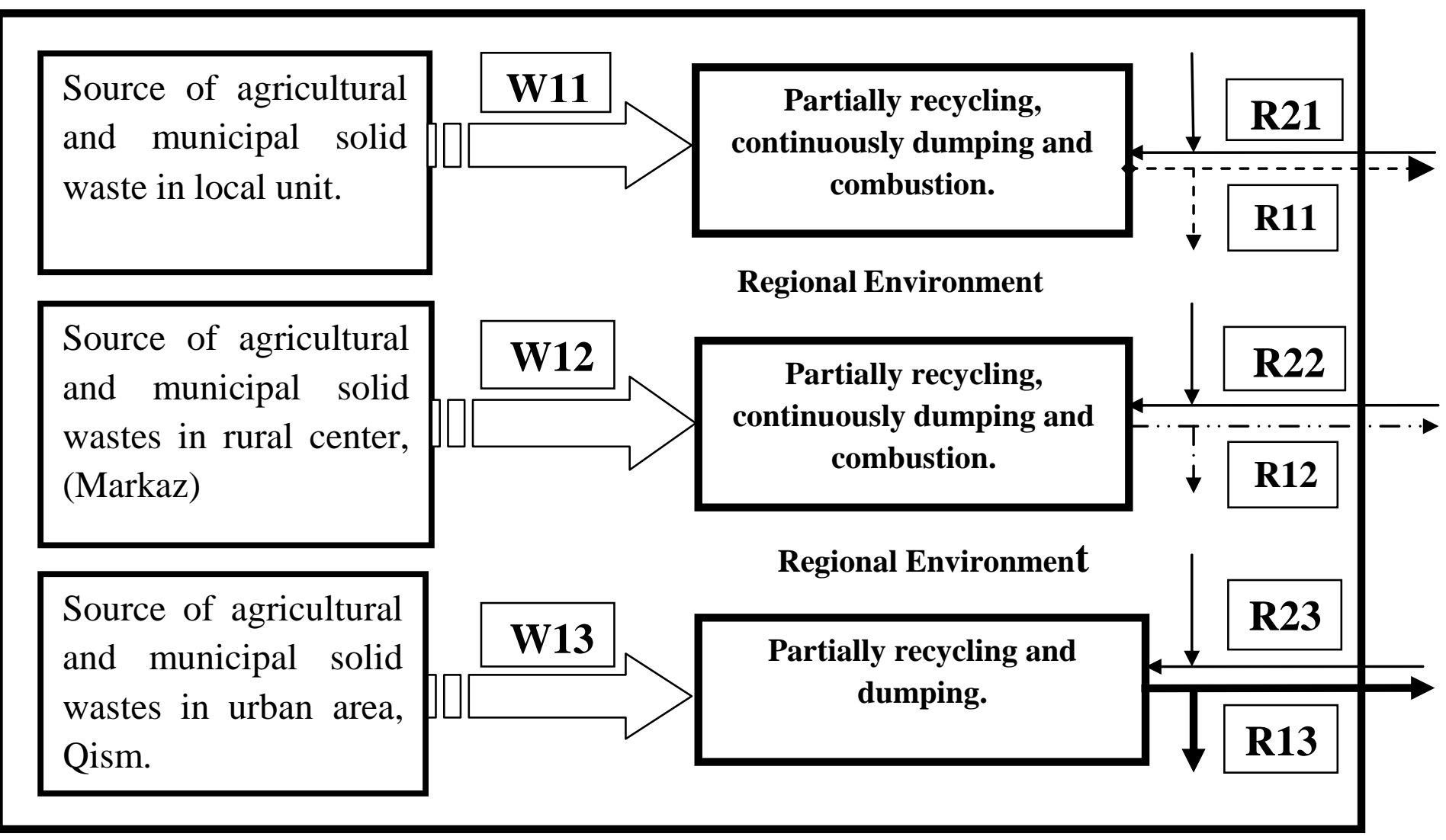

Fig. (3): The observed approaches for getting rid of the solid wastes in the planning regions. 
Specific parts of R21, R22, and R23 participate inside the region and the remainder parts are transferred to other regions. R31, R32, and R33 are assumed symbols expressing specific parts of the solid waste and its side effects from other regions.

However, environmental development strategic plans are needed for overcoming the problem of the agricultural and municipal solid wastes in Egypt. These strategic plans must to be built on specific principles assuring the continuity of the solid wastes management in the planning regions. These principles could be summarized in the following points: a) Economically: For assuring the economic efficiency, both the agricultural and the municipal solid wastes are considered economic renewable resources with negative values having their impacts on the source of generation. b) Environmentally: The separation of the industrial solid wastes and the MSW through managing process must be done to avoid heavy metal problems. c) Practically: It is ideal, but may be possible to have zero waste accumulation and complete recycling for both the agricultural and municipal solid wastes. d) Professionally: It is possible to establish integrated industries for recycling both the agricultural and the municipal solid wastes for minimizing transportation costs. e) Politically: Enhancing the private sectors is very important for investing more assets in solid waste recycling plants and recycling industries on different levels. f) Technically: Starting separation processes at the generation source of both the agricultural and the municipal solid wastes is possible and have highly positive impacts. g) Regulatory: License confiscating has to be immediately done on both the agricultural and the industrial projects neglecting waste recycling obligations. h) Socially: The safe solid wastes recycling process has to be one of the main issues in culture of both urban and rural residents' area. i) Physically: Planning and design of the agricultural and the municipal solid wastes plants must be considered one of the public utilities and services in the Local Unit, Rural Makaz, and urban area of the planning regions. j) Environmentally: 
Constructing the closed system recycling units inside the region is obligatory for conserving the regional environment.

Therefore, construction of planning alternatives for local allocation of the agricultural and the municipal solid wastes management units within the regions is considered the critical issue in the environmental development strategy. However, four alternatives dealing with the local allocation of the MSW management units in the planning regions could be summarized as follows: (1) Establishing sanitary large scale recycling units in the backward desert of the new cities for managing both the agricultural and the municipal solid wastes of the hole region, as considered the first alternative and mentioned in the results section and seen in Fig. (4). This alternative has its advantages such as low cost of infrastructures needed for constructing the MSW management units, close to the new cities and near to the urban areas generating the huge amounts of the MSW, as that mentioned in the result above, easy to develop integrated recycling industries and easy to manage and control on the system by the local administration. The disadvantages of this alternative are many types of difficulties and high costs to transport the MSW from the traditional rural areas of the region. (2) Establishing both large and medium scale recycling units at the urban areas and the rural Markaz is considered second alternative, as mentioned in the results and seen in Fig. (5). Briefly, the large scale units could be used for serving the urban areas, and the medium scale unit for serving rural Markaz and its Local Units. The advantages of this alternative are minimizing the cost of the MSW transport from the rural areas; creating real chances for employment and investment in the Rural Markaz; and decreasing the impacts on the urban areas of the region. The disadvantages of this alternative are many difficulties in transporting the MSW from the local units to the Rural Markaz due to the lack of transportation facilities and inefficient road network at the local Units. 


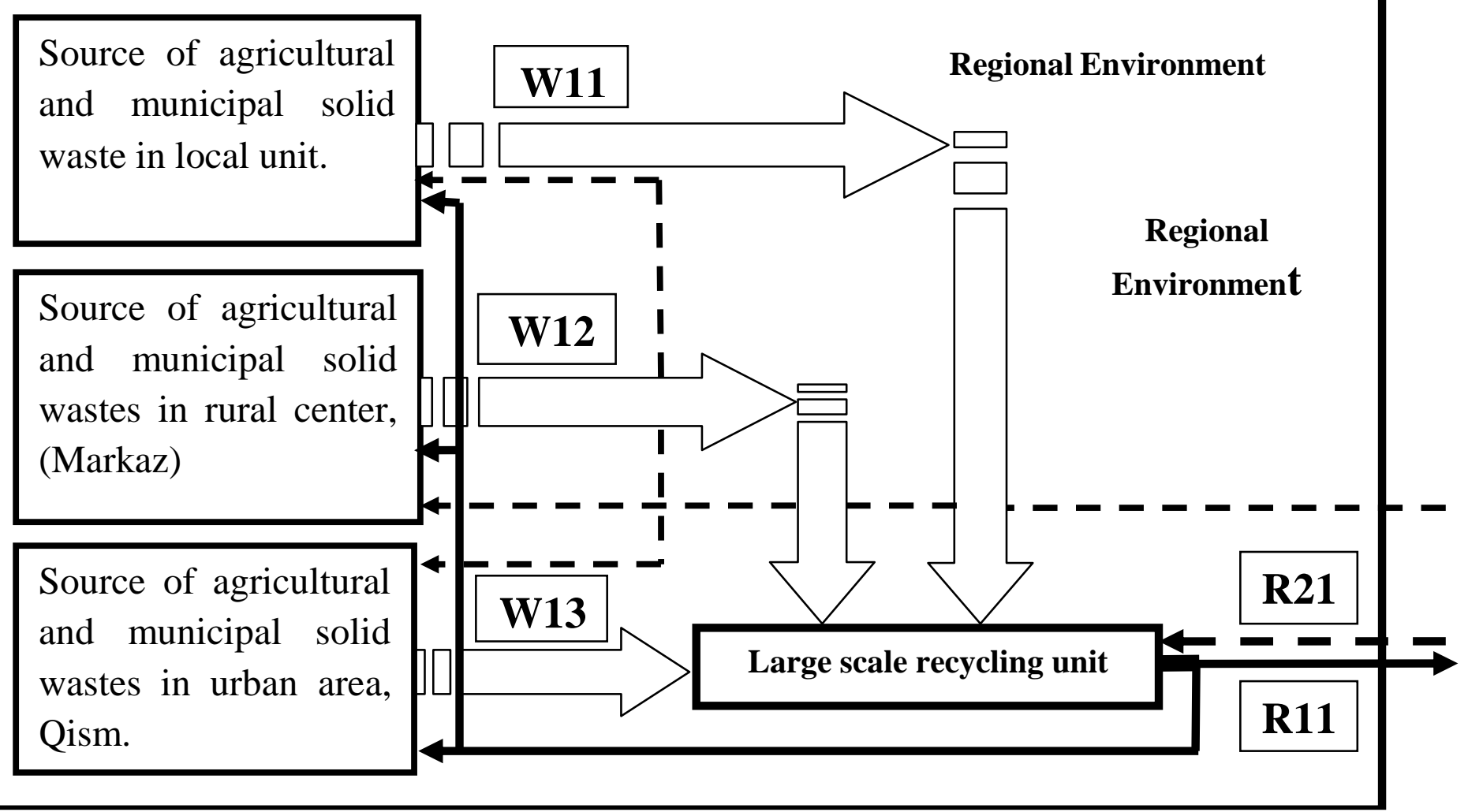

Fig. (4): The first alternative of the environmental development strategy in the planning regions. 


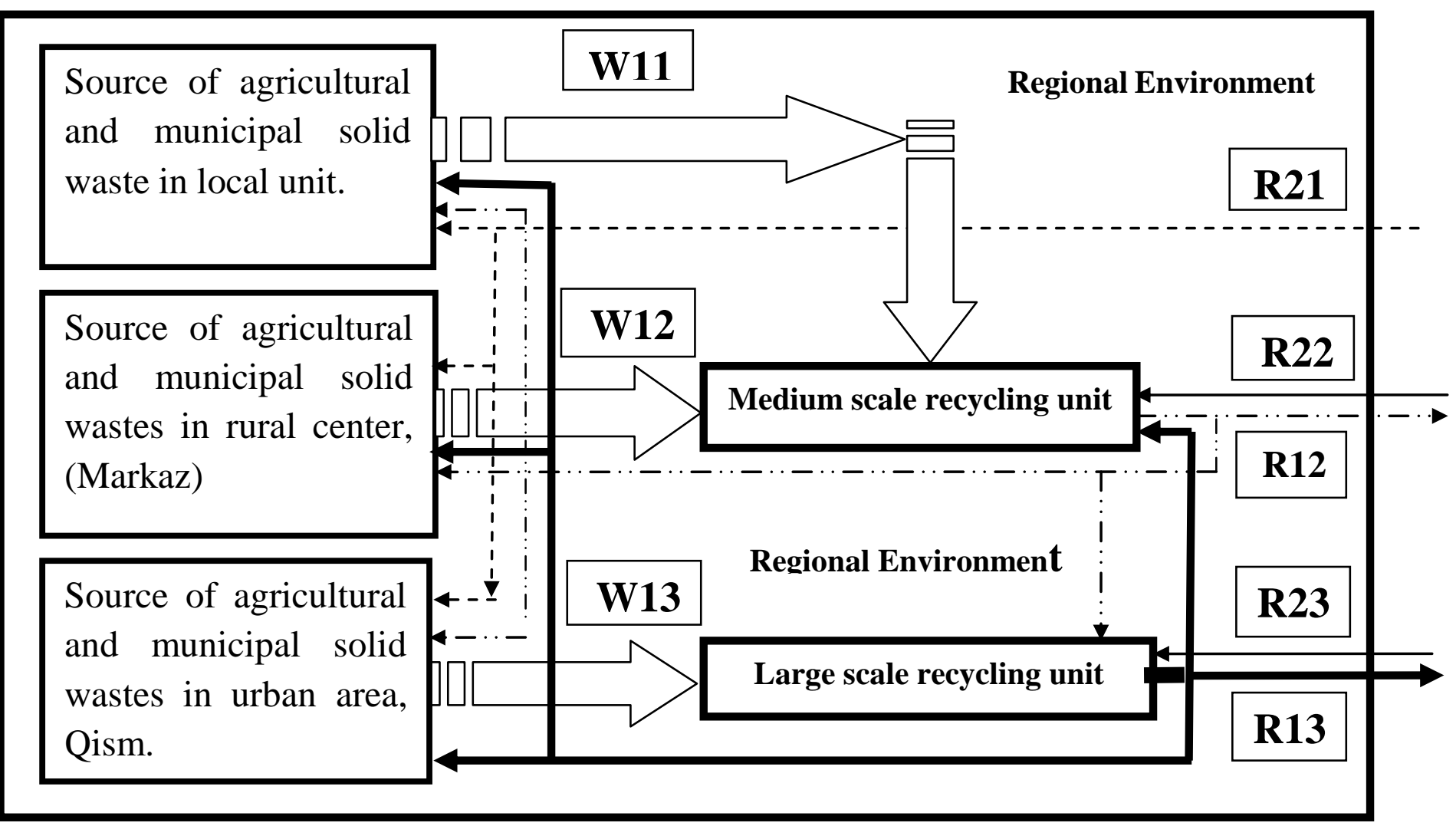

Fig. (5): The second alternative of the environmental development strategy in the planning regions. 
(3) Establishing small scale recycling units for managing both the agricultural and municipal solid wastes generated from the rural areas at the Local Units. Also, establishing large scale recycling units for managing both the agricultural and municipal solid wastes generated from the urban areas and the rural Markaz as mentioned in the results sections and seen in Fig. (6). The advantages of this alternative are minimizing the cost of the MSW transport from the Local Units; creating real chances for employment and investment in the Local Units; and decreasing the impacts on the urban areas and Rural Markaz of the region. The disadvantages of this alternative are many types of difficulties to keep the agriculture lands from the urbanization growth at the local Units. (4) Establishing small scale recycling units, medium scale, and large scale recycling at Local Units, Rural Markaz, and urban areas respectively, as mentioned in the results section and as seen in Fig. (7). The advantages of this alternative is minimizing the cost of the MSW transport. The disadvantage of this alternative is the need of a highly efficient system for controlling the widespread recycling units within the region.

Evaluation of the alternatives: Environmentally, applying the sanitary conditions roles in planning, design, and management processes of the solid waste recycling units are completely enough for the environmental conservation on the surroundings inside the region. Therefore applying any one of the four alternatives under this condition hasn't any type of side effects on the surroundings. Economically, due to the local allocation of each one of the four alternatives are completely different therefore the expected costs of the solid wastes transfer will be different. In the evaluation process of the four alternatives transportation distances and daily generation of the solid wastes were calculated using the designed simulation layout for the planning regions maps in Egypt. Also, transfer cost for each ton per hour, and available traffic speed on the road network were calculated depending on the field study. The application of the designed planning indicator (DCSWT) on the four alternatives revealed that the fourth alternative of the environmental development strategy is ranked in the first grade, as shown in table (10). 


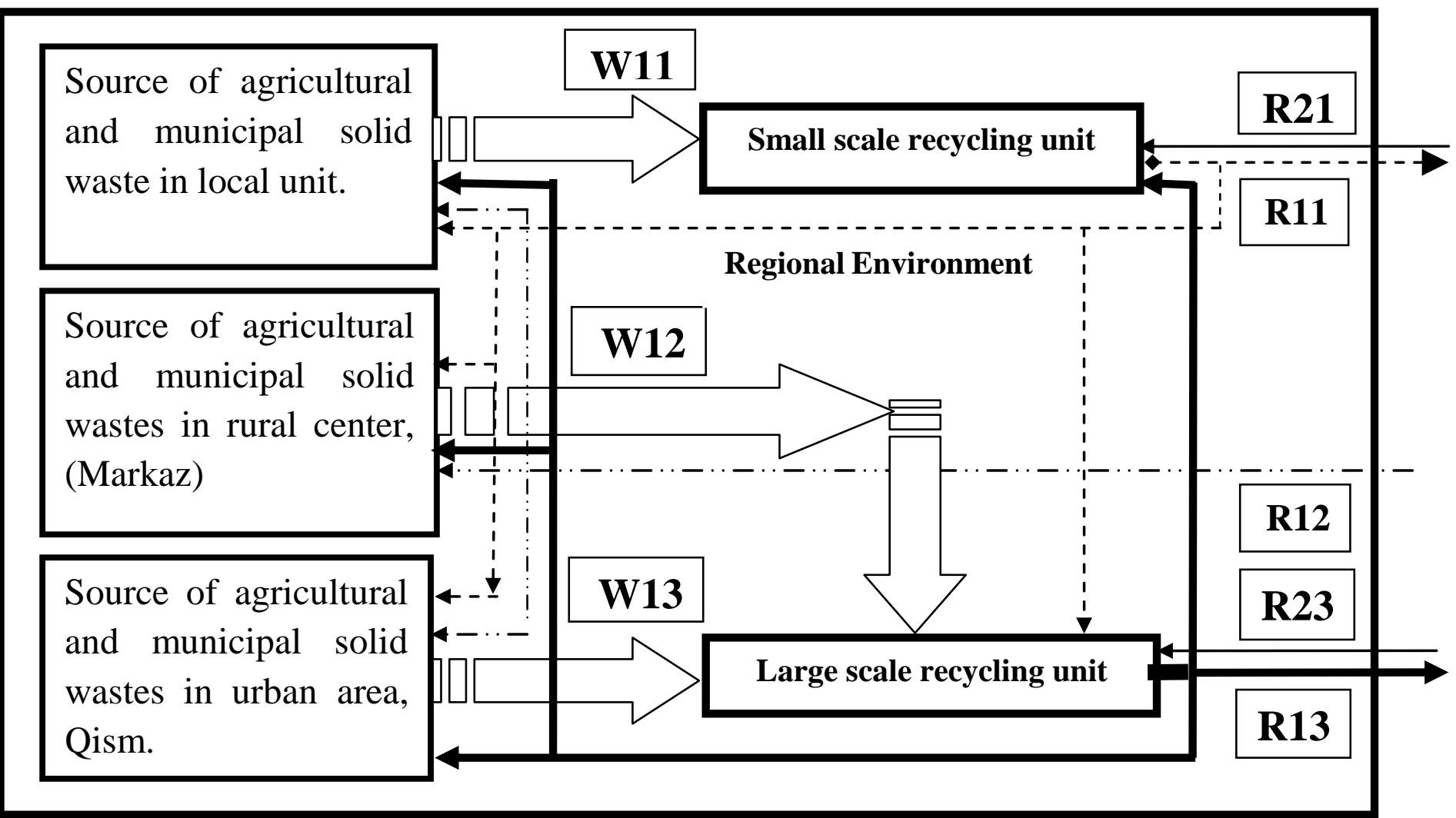

Fig. (6): The third alternative of the environmental development strategy in the planning regions. 


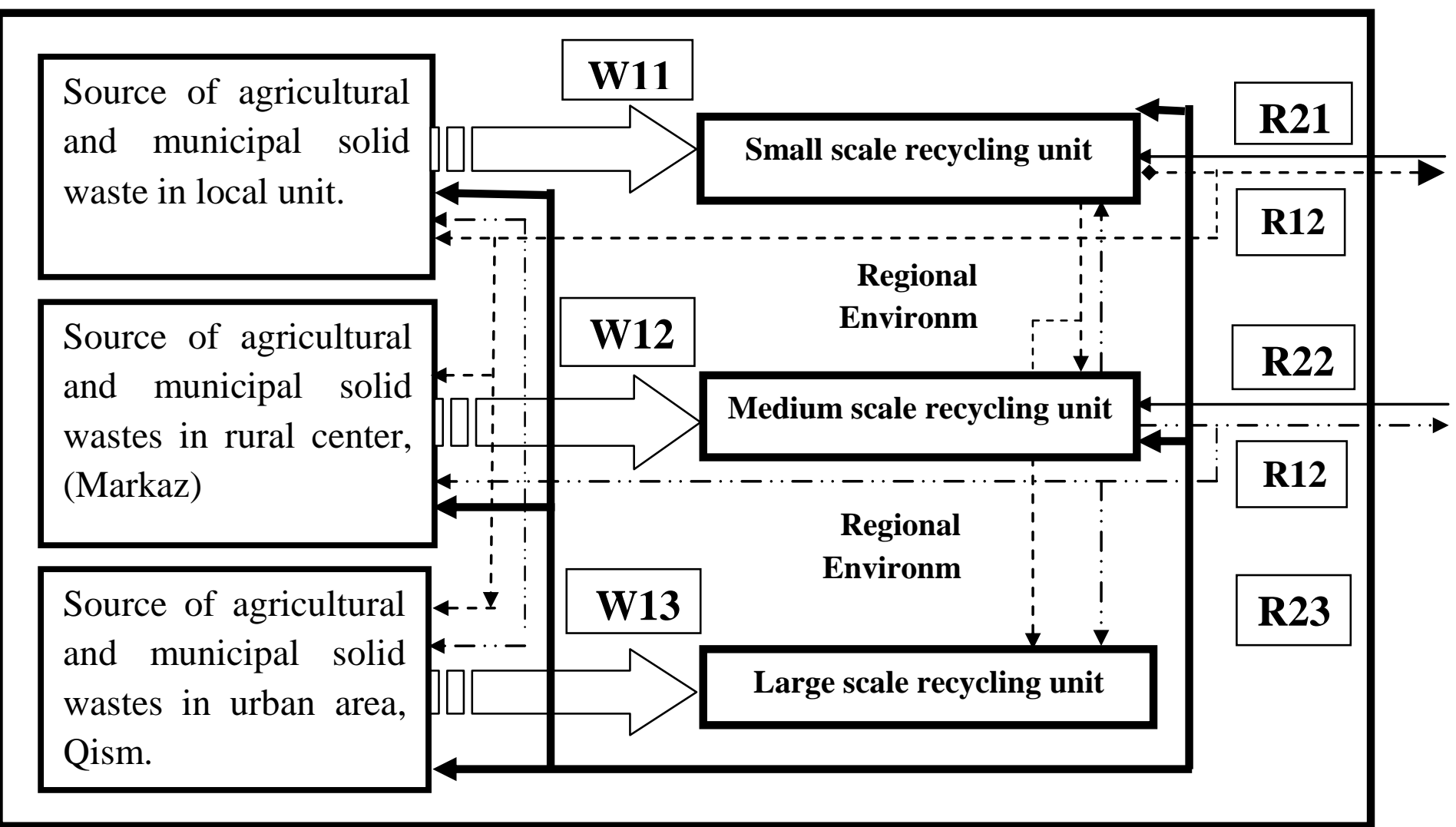

Fig. (7): The fourth alternative of the environmental development strategy in the planning regions. 
Table (10): Evaluation of the designed alternatives for the environmental development strategies in the planning regions.

\begin{tabular}{|c|c|c|}
\hline $\begin{array}{c}\text { Environmental } \\
\text { Development Strategy } \\
\text { Alternatives }\end{array}$ & $\begin{array}{c}\text { Transfer Costs of } \\
\text { the Daily Solid } \\
\text { Wastes }(\boldsymbol{L E})\end{array}$ & $\begin{array}{c}\text { Alternatives } \\
\text { Rank }\end{array}$ \\
\hline $\begin{array}{c}\text { Large Scale Recycling } \\
\text { Units }\end{array}$ & 98800 & The fourth \\
\hline $\begin{array}{c}\text { Large and Medium Scale } \\
\text { Recycling Units }\end{array}$ & 45600 & The second \\
\hline $\begin{array}{c}\text { Large, and Small Scale } \\
\text { Recycling Units }\end{array}$ & 53500 & The third \\
\hline $\begin{array}{c}\text { Large, Medium, and Small } \\
\text { Scale Recycling Units }\end{array}$ & 37800 & The first \\
\hline
\end{tabular}

This result means applying the large scale recycling units only in the all planning regions in Egypt is considered a technical mistake in the environmental development strategy.

\section{SUMMARY AND COCLUSION}

The agricultural and municipal solid wastes are considered one of the main problems in the national, regional, and local levels in Egypt. The main objective of this research is to construct environmental development strategic plan under continual generation of the solid wastes. Really, this objective means conserving regional environment, utilizing both agricultural and municipal solid wastes as rentable economic resources, saving huge amounts of the financial assets, treating hazards of solid waste pollution, creating new jobs inside the region, finding huge amounts of raw materials in recycling activities, enhancing industrial processes of MSW equipment inside the region, attracting the financial assets at MSW activities, and helping great services to the tourist sector inside the region.

Data collection, manipulation, field study, and spatial analysis revealed: 1) Annually, the total amounts of the municipal solid wastes in Egypt are 15 million tons. 2) In high income areas, collection efficiency can reach $60 \%$, in contrast to $10 \%$ collection efficiency in rural low income areas. 
3) Municipal solid waste ingredients in Egypt are 50-60\% organic material, $10-25 \%$ paper, $3-12 \%$ plastic, $1-5 \%$ glass, $1.5-7 \%$ metals, $1.2-$ $7 \%$ rags, and $11-30 \%$ other. 4) Greater Cairo Region generates $52 \%$ and $14 \%$ of municipal solid wastes of the urban and rural areas of Egypt respectively. 4) Due to the activity of the illegal scavengers, percentage of the organic material, paper, plastic, and metal in the fresh samples are greater than their values in the stale samples collected from the garbage lots. 5) 6 Oct. Governorate generates 1296.430 ton per day and does not have any municipal solid waste plants until now.

The ten points of planning principles and the four diagrams of planning alternatives for environmental development strategic plan are considered the main results of this research. The research recommendations are: Keeping in mind the eight principles and the four alternatives in preparation processes of the strategic regional plan is first recommendation. Keeping the balance among planning of the facilities of the solid wastes management and planning of the facilities of the other services and public utilities in the region as the second recommendation. Executing future studies on planning and design criteria of the MSW recycling units in the planning regions.

\section{REFERENCES}

Al-Salem, S.M. (2009) Life cycle assessment (LCA) of municipal solid waste management in the state of Kuwait- Euro. J, of Sc. Res., 34 (3), pp:395-405.

Asakura, H. Matsuto, T. and Inoue, Y. (2010) Adopted technologies and basis for selection at municipal solid waste landfill facilities constructed in recent years in Japan- Waste Manag. Res, 28 (8), pp:685-694.

CAPMS (2010) Annual report of environmental statistics, No. 7112800/2008 - Cen. Age. for Publ. Mobiliz. and Stat., Egypt, pp: 50-71

EAS (2010) Price and quantity of straw and stalks produced from summer, nili, and winter crop yields in Egypt. Ministry of Ag., Eco. Affair Sec. (EAS), Egypt,: pp 
Erkuta, E. Karagiannidisb, A. Perkoulidisb, G. and Stevanus A. and Tjandrac, B. (2008) A multi-criteria facility location model for municipal solid waste management in North Greece-Euro. J of Oper. Res., 187 (3), pp: 1402-1421.

Gallardo, A. María D. Boveaa, F. Colomera, J. Pradesa, M. and Carlosa, M. (2010) Comparison of different collection systems for sorted household waste in Spain-Waste Managt (30)12 :pp24302439 .

Hostovsky, C. (2005) Integrating Planning Theory and Waste Management - an Annotated Bibliography - Resources, Conservation and Recycling, Volume 45, Issue 2, Pages 142-158

Huang, Y. F. Baetz, B. W. Huang G. H. and Liu, L. (2002) Violation analysis for solid waste management systems: an interval fuzzy programming approach Journal of Environmental Management. Volume 65, Issue 4, Pages 431-446.

Jasem, M. A. (2005) Municipal solid waste recycling in the Gulf Cooperation Council states, 45( 2), pp : 142-158.

Mutuku A. Mwanthi; L. O. Nyabola; E. and Tenambergen D. (1997) The present and future status of municipal solid waste management in Nairobi -Inte. J. of Env. Health Research, 7(4) :pp 345 - 354.

Noche, B. Rhoma, F.A. Chinakupt, T. and Jawale, M. (2010) Optimization model for solid waste management system network design case study -Comp. and Auto. Eng. (ICCAE), The 2nd Inter.Con.5,pp:230-236.

Ravindrana, B. and Sekaran, G. (2010) Bacterial composting of animal fleshing generated from tannery industries- Waste Management,30 (12), pp:2622-2630.

Saeed, M. O. Hassan, N. N. and M. Abdul Mujeebu, A. (2009) Assessment of municipal solid waste generation and recyclable materials potential in Kuala Lumpur, Malaysia, Waste Manag. 29, (7), pp:2209-2213. 
Saxena, S. Srivastava, R.K. and Samaddar, A.B. (2010) "Towards sustainable municipal solid waste management in Allahabad City", Manag. of Env. Quality: An Inter. J, 21 ( 3) pp: 308 - 323.

Thorneloe, S. A. Keith A. Weitz, K. A. and Miller, J. (2009) Analysis of the zero waste management option using the municipal solid waste decision support tool- Proceedings of the 17th Annual North American Waste-to-Energy Conference NAWTEC 17 May 18-20, 2009, Chantilly, Virginia, USA.

Tralhão, L. Rodrigues, J.C. and Almeida, L.A. (2010) A multiobjective modeling approach to locate multi-compartment containers for urban-sorted waste- - (30) 12, pp: 2418-2429.

UCL \& ER (2008) Unified Construction Law, No. 119, 2008, and its Executive Regulating, No. 144, 2009- Issued by Decision of Mister of Housing, Egypt.pp:6-25.unVao day nghe bai nay di ban

Yau, Y. (2010) Domestic waste recycling, collective action and economic incentive: The case in Hong Kong-Waste Management, 30 (12), pp: 2440-2447.

Zhang, X. Huang, G. H. Xianghui, N. Yumin, C. and Qianguo L. (2010) Planning of municipal solid waste management under dual uncertainties- Waste Manag. Res. 28 (8), pp: 673-684.

Zia, H. and Devadas, V. (2007) "Municipal solid waste management in Kanpur, India: obstacles and prospects", Manag. of Envir. Quality: An Inter. J., 18 (1), pp: $89-108$.

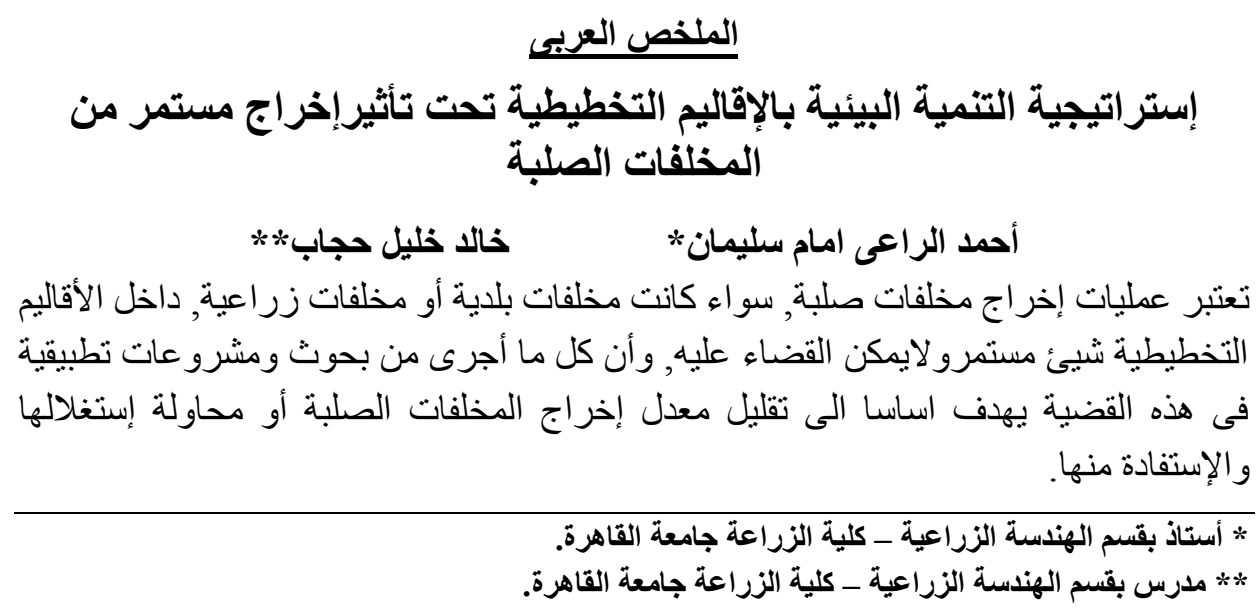


ونظر العدم إرتباط هذه الجهود بخطط التنمية الإقليمية, فإن المحصلة النهائية محدودة القيمة, ويستدل على ذلك بتر اكم كميات كبيرة من المخلفات الصلبة داخل الإقاليم التخطيطية, مما يشكل كارثة بيئية ومحددا قويا لعمليات التنمية الإقليمية. حيث يشير التقرير السنوى لإحصائيات البئئة CAPMS (2010)

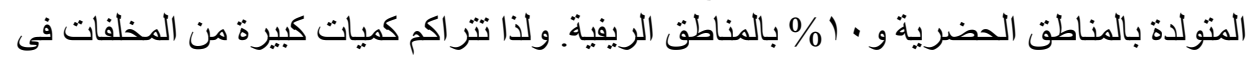

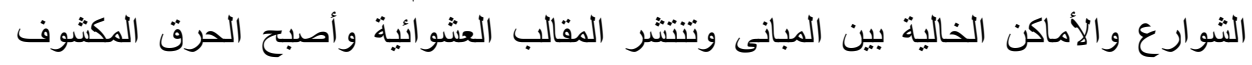
للمخلفات هو الوسيلة الرئيسية للتخلص منها, ويشكل ذلك أهم مصادر التلوث فى مصر. ولذا فإن الهدف من هذا البحث هوالوصول الى إستراتيجية مناسبة للتنمية البيئية بالأقاليم التخطيطية تحت تأثنر الإخراج المستمر للمخلفات الصلبة بإعتبار ها أحد المحددات الرئيسية

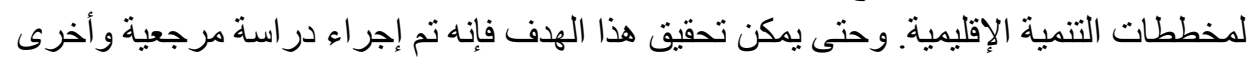
ميدانية للتعرف على نو عيات وحجم المخلفات البلدية الصلبة و الزراعية داخل الأقاليم التخطيطية

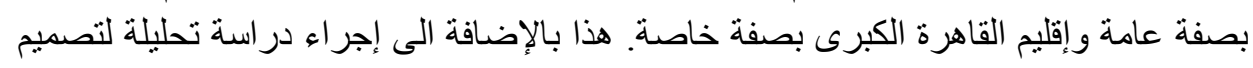

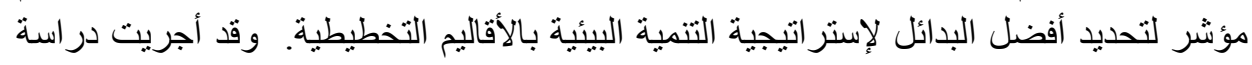

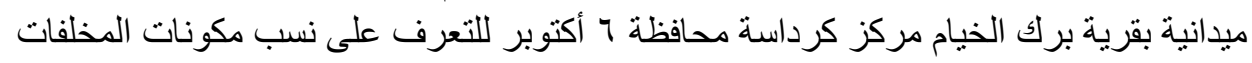

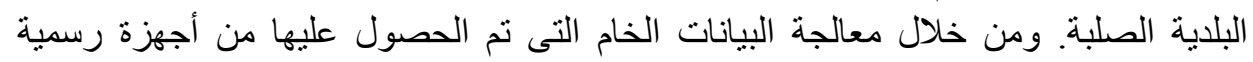

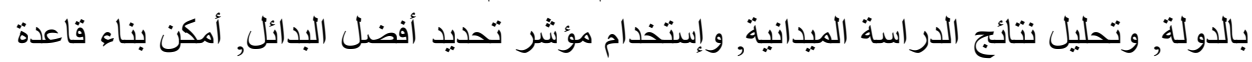

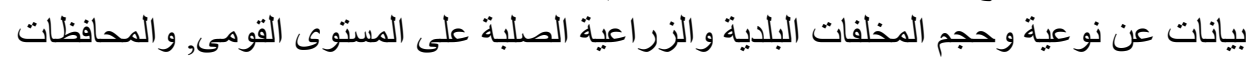

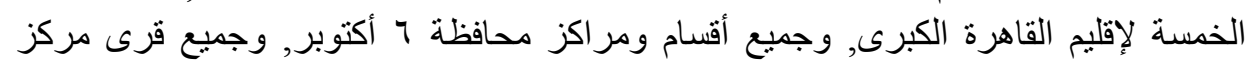

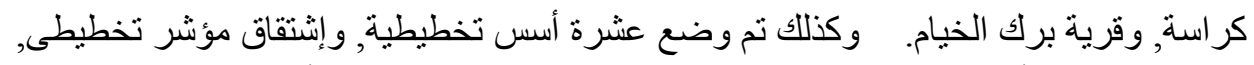

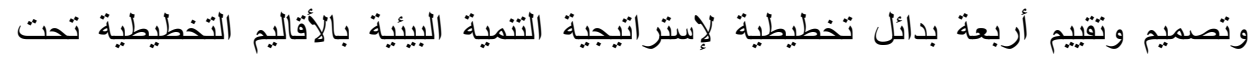

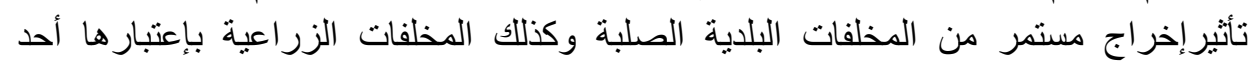
المحددات الرئيسية لمخططات التنمية الإقليمية. وقد أوصى البحث بثلاث نقاط أساسية وهى: (1)

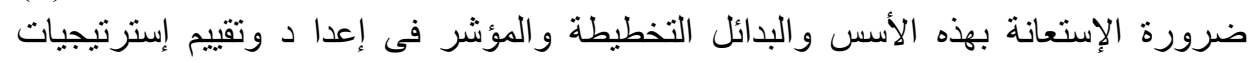

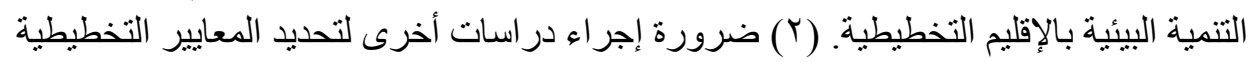

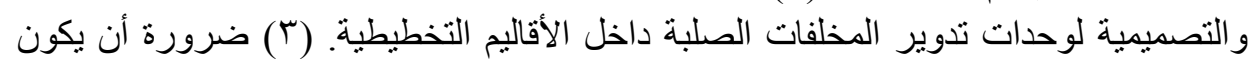

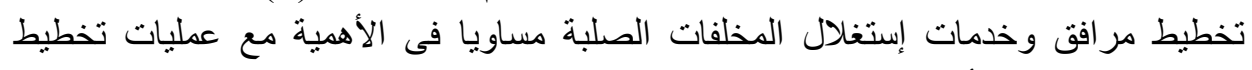
المر افق و الخدمات الأخرى داخل الإقليم. 